\title{
Employment of Entry-Level Journalists- Case of Georgia
}

\author{
Mariam Gersamia \\ Lead author, professor at Ivane Javakhishvili Tbilisi State University,
}

Maia Toradze

Associate professor at Ivane Javakhishvili Tbilisi State University

\begin{abstract}
The purpose of this research is to identify the common criteria (knowledge and skill-based competences) which employers consider in the process of employing young journalists. The research holds significance for adjusting educational programs and accreditation standards. This research answers the following questions: 1 . According to what criteria are entry-level journalists employed in Georgia? 2. What specific knowledge and skills are more attractive for employers? 3. Do employers take into consideration what University was attended, specific qualifications and earned degrees? Employers from 25 media organizations answered questionnaires (with close and open-ended questions). According to the results, only $40 \%$ of interns are paid in Georgia. While employing journalists "writing and editing skills" (88\%) are the most important ones. Employers consider that "meeting deadlines" and an ability to work with new technologies are important skills as well (76\%). $52 \%$ of employers prioritize a profound knowledge of a specific field (besides journalism). It is worth mentioning that $84 \%$ of respondents give preference to the competences gained in specific fields such as economy, politics, arts, etc. According to employers' opinion, journalists gain more theoretical knowledge than practical at universities. For the majority of employers, practical knowledge is more essential. According to survey results, the specific recommendations have been produced for the media educational sector.
\end{abstract}

Keywords: Employment, Entry-Level Journalists, Georgia, media education

\section{Introduction}

According to the official and latest data (2016) the level of unemployment in Georgia reaches 12 percent, more precisely, 37 percent from this data refers to those between 25 and 30 . This is the precise age when students and graduates actively begin seeking jobs. The data stays high (30\%) among $20-24$ youths ${ }^{1}$.

There is no information in Georgia on how many journalists (journalists included) are employed in the media sector. According to IREX recent research (MSI, 2017, p. 168)2 the number of active media organizations are as follows:

print media: 313 newspapers (Georgian national service of statistics, 2015);

television: 41 satellite, 54 digital and 76 cable channels;

radio stations: 76 (Georgian National Communications Commission, 2015)

news agencies: 31 (www.yellowpages.ge)

According to National Assessment and Examinations Centre data (www.naec.ge; last visit January; 2017) and National Centre for Educational Quality Enhancement (www. eqe.ge; last visit January, 2017) there are 40 accredited educational

\footnotetext{
${ }^{1}$ National Statistics office of Georgia, employment and unemployment http://geostat.ge/?action=page\&p_id=145\&lang=geo (last visit on Jan 20, 2018)

2 Media Sustainability Index 2017, IREX, https://www.irex.org/sites/default/files/pdf/media-sustainability-index-europeeurasia-2017-full.pdf (last visit on Jan 20, 2018), p. 168
} 
programs for media/journalism and/or mass communication. Among them are two professional educational programs, 23 undergraduate, 13 - Master and two - doctoral programs.

The goal of this research is to find out what requirements employers have and what criteria (knowledge and skill-based competences) they consider in the process of employing young (entry-level) journalists or while choosing interns; what recommendations they give to media educational sector etc. The research is a valuable resource for educators in modernizing educational programs by taking into consideration employment requirements and fine-tuning accreditation standards.

\section{Literature review}

The employment of Journalists has been studied from various angles, such as the influence of social links and education (including the skills - how to use new technologies), the status of the University (how prestigious it is), internship opportunities, meritocracy based education, gender, race and ethnicity, involvement in activities beyond curriculum and others.

British experts investigate "how networks and connections aid the "educational elite" to gain entrance into the upper echelons of the graduate labor market in two countries: France and England". Authors (Tholen, Brown, Power, Allouch, 2013) ${ }^{1}$ mention, that status of the university "becomes especially relevant within debates on the meritocratic nature of the post-industrial labor market. Using interview data from final year students from two elite higher education institutions... it is assessed whether their elite educational experiences are translated into networks and connections that aid their future labor market positions" (2013, p. 142). The authors discuss the issue: what is the main reason for employment: academic achievements or class and elite privileges? British researchers prove that elite educational institutions support their graduates to establish links on the job market. In this research, we will observe the results connected with employer expectations, from this angle.

In other researches, (Montgomery, 1991; Mouw, 2003) authors focus on the fact that in the labor market social connections are very significant (family, friends, etc.). According to SuttonTrust (2009)2, "educational elites" have substantial access to prestigious positions in the labor market. The above-mentioned research shows that developed networks and connections play a huge role for the elite students in terms of their future employment. Students realize that there is a tendency that people with the same social cultural and educational backgrounds will be accepted and welcomed into jobs. Abovementioned authors (Tholen, Brown, et al, 2013)3 , pay attention to the connections as a part of educational experience. In their opinion, "Education plays a crucial role in providing networks and connections but also legitimizing it. There was a strong sense among the students that the networks and connections are a result of their talent and social exclusivity of their education. Their education does provide excellent opportunities to create a network of useful contacts."(2013, p. 146) ${ }^{4}$. Researchers pay attention to the role of academic circles in broadening the networks and connections and in employing acquaintances. The researchers (Tholen, Brown, et Al, 2013) mention that students "did not exclusively use educationrelated networks and connections but would also utilize connections through friends, family and fellow-students" 5 .

Rivera $(2011)^{6}$ focuses on the point that so-called elite employers select the graduates from the most prestigious/ elite Universities and they mostly pay attention to this particular fact rather than education quality. Research conducted in the USA highlights that "the gap between employer-requirements and journalists" revealed that in employers' opinion, graduates

\footnotetext{
${ }^{1}$ Gerbrand Tholen, Phillip Brown, Sally Power, Annabelle Allouch, The role of networks and connections in educational elites' labour market entrance Gerbrand Tholena, Research in Social Stratification and Mobility 34 (2013) 142-154. Published by Elsevier Ltd., Available online at www.sciencedirect.com

2 Sutton Trust is a British organization, think-tank and do-tank. See more http://www.suttontrust.com/ (last seen on October 15, 2016)

${ }^{3}$ Gerbrand Tholen, Phillip Brown, Sally Power, Annabelle Allouch, The role of networks and connections in educational elites' labour market entrance Gerbrand Tholena, Research in Social Stratification and Mobility 34 (2013) 142-154.

Published by Elsevier Ltd., Available online at www.sciencedirect.com

${ }^{4}$ Ibid, p. 146

5 lbid, p. 149

${ }^{6}$ Rivera, L. A. (2011). Ivies, extra curriculars, and exclusion: Elite employers' use of educational credentials. Research in Social Stratification and Mobility, 29 (1), 71-90.
} 
don't have enough skills to begin working right after graduation (Adams, 2008; Lepre \& Bleske, 2005; Mattern, 2003; McDonough, Rodriguez \& Prior-Miller, 2009). The survey conducted in Georgia claims the same.

Internship is an importance practice in terms of broadening networks and connections as well. In addition, internship is an opportunity for professional growth and finding an appropriate job. British authors make it clear that besides the abovementioned factors, social events and self-realization are also essential. During internship, students shape their skills, investigate spheres of their own interests, and evaluate their strengths and weaknesses. An internship is the main platform where students match their skills to the labor market requirements.

The main issue of this topic is to find answers to the following questions: How do students find an internship? Do they address theirs tutors or use personal contacts?

From this perspective, it is worth identifying what employers pay attention to and what their priorities are (e.g. particular skills, University degree, letters of reference, work experience, personal characteristics, emotional and intellectual quotient (EQ \& IQ), etc.).

Hines and Basso (2008) found that "an alarming number of communication professionals report that entry-level employees possess poor writing skills and even poorer editing skills" (p. 293) ${ }^{1}$. The results and the parallels of our research show an interesting picture from this point of view.

Researchers (Wegner and Owens, 2013) have developed a coding sheet after analyzing hundreds of job postings and noting the most common skills and attributes requested. According to the research:

"Thirty-five skills and attributes were coded for accuracy, aggressiveness, news judgment, creativity, storytelling, enterprising, willingness to work under pressure/ tight deadlines, team player, willingness to work long hours, strong writing, proofreading skills, ability to develop sources, previous professional experience, communication skills, leadership, ability to multitask, production/field production experience, software knowledge, shooting/photography skills, nonlinear editing skills, web/multimedia skills, design skills, experience posting to the web, Cascading Style Sheets (CSS) knowledge, HTML knowledge, Content Management System knowledge, Adobe Photoshop skills, Adobe Illustrator skills, AVID editing software skills, Final-Cut skills, experience writing for the web, Search Engine Optimization (SEO) skills, web analytics skills, social networking and mobile application skills".

According to this research, employers in broadcast-media consider previous professional experience as very important $(98.6 \%)$, same refers to accuracy in writing $(84.9 \%)$, leadership $(71.2 \%)$, willingness to work under pressure/tight deadlines $(69.9 \%)$, news judgment (56.2\%). Also worth mentioning is that work experience is one of the most important point in the case of Georgia.

American researchers (Becker, Han at al., 2014) 3 measured the influence of extra-curricular activities on students, future employment. They have proved that such activities have a significant impact, at least upon the initial phase of entry to the labor market (2014, p. 355). They suggest that journalistic extra-curricula activities (preparing the annual issue, school newspaper and broadcasting programs) have positive effects on career decisions (p. 347), planning and on the success of the university graduates once they move into the job market" (p. 354). Regrettably, similar research has not been conducted in Georgia.

\footnotetext{
1 Hines, R., \& Basso, J. (2008). Do communication students have the "write stuff"?: Practitioners evaluate writing skills of entry-level workers. Journal of Promotion Management, 14, 293-307.

2 Deb Wenger and Lynn C. Owens, An Examination of Job Skills Required by Top U.S. Broadcast News Companies and Potential Impact on Journalism Curricula, 2013, Electronic News, 7(1) 22-35; Downloaded from enx.sagepub.com at Tbilisi State University on October 9, 2016 ; p. 26.

3 Lee B. Becker, Edmund Laufi and Wilson Lowrey, Differential Employment Rates in the Journalism and Mass Communication Labor Force Based on Gender, Race, and Ethnicity: Exploring the Impact of Affirmative Action, Journalism and Mass Communication Quartarly, Vol. 76, No. 4 1999, p. 631-645. Downloaded from jmq.sagepub.com at Tbilisi State University on October 9, 2016
} 
One of the vital competencies in a journalist's career is an ability to adapt to new technologies. Media researchers from Greece (Veglis, Pomporstsis, 2014) ${ }^{1}$ were interested in using information and communication technologies (ICT) by journalists and studied the specific skills, which were necessary for journalists to work successfully. According to the research conducted by them, journalists do not have enough skills to use communication technologies (ICT) in their work. Researchers suggest updating educational programs and acquiring future journalists with the knowledge and skills of - ICT tools ${ }^{2}$.

Swede author (Henrik Ornebring, 2010) ${ }^{3}$ discusses the integration of technology into the everyday working practices of journalists. He suggests that that interaction "remains an important reason for the continuing strength of this technological paradigm" and concludes, "Relationship between journalism and technology uses the concept of labour as a lens through which we can see the relationship between journalism and technology in a different way" (p. 58-59)4. Indeed, it seems hard not to agree with the opinion, that "when journalists are required to learn digital production techniques in order to create content for different media platforms, that represents tangible changes in their working lives, changes that are readily perceived as being 'caused' by technology" (p. 58) 5 . Even in this perspective, the basic journalistic competencies like good writing and editing, information gathering skills historically have been viewed as more important than technical skills specific to the medium in which the journalist works (Huang, 2006; Singer, 2004) ${ }^{6}$. From this point of view, the research conducted in Georgia produces important information for further discussions.

\section{Research design, methodology and procedures}

Qualitative and quantitative content analysis has been used for this research. A questionnaire (with open and close-ended questions) has been used as a survey instrument. The questions have a comment space/area. The number of questions is 20. Research questions are the following:

RQ1: According to what criteria are entry-level journalists employed in Georgia?

$\mathrm{RQ2}$ : What specific knowledge and skills are more attractive for employers?

RQ3: Do employers take into consideration the University, qualifications and earned degrees?

Research period: the research (questioning employers) was conducted in September-October, 2017

Sampling: The questionnaire was sent online to 36 employers in the capital of Georgia and regions (in September 2016). The employers were chosen from nation-wide TV channels, newspapers, on-line publishers, non-governmental and research organizations focused on journalism studies; According to the preliminary agreement, the questionnaire was completed by those high ranking managers who are in charge of employing new people or selecting them for internship.

The completed questionnaires were received from 25 media organizations. Among them $44 \%(n=11)$ were from broadcastmedia, $24 \%(n=6)$ from online media and $20 \%(n=5)$ from printed media. These organizations are:

- $\quad$ Public Broadcaster - $1^{\text {st }}$ Channel;

- Broadcasting Company "Rustavi 2";

- Broadcasting Company "Maestro";

\footnotetext{
${ }^{1}$ Andreas Veglis and Andreas Pomportsis, Journalists in the Age of ICTs: Work Demands and Educational Needs, Journalism \& Mass Communication Educator, 2014, Vol 69 (1) 61-75, jmce.sagepub.com, Downloaded from jmc.sagepub.com by guest on October $8,2016.33 \cdot 61-62$

2 Ibid

${ }^{3}$ Henrik Örnebring, Technology and journalism-as-labour: Historical perspectives, University of Oxford, UK, Journalism 11(1) 57-74, Downloaded from jmc.sagepub.com by guest on October 8, 2016.

${ }^{4} \mathrm{lbid}$, p. $58-59$

$5 \mathrm{lbid}$

${ }^{6}$ Huang, E. (2006) 'Facing the Challenges of Convergence: Media Professionals' Concerns of Working across Media Platforms', Convergence 12(1): 83-98. And Singer, J. B. (2004) 'More than Ink-stained Wretches: The Resocialisation of Print Journalists in Converged Newsrooms', Journalism and Mass Communication Quarterly 81(4): 838-56.
} 
- Broadcasting Company "TV Pirveli";

- Broadcasting Company "GDS";

- Georgian Association of Regional Broadcasters;

- Media holding "Fortuna";

- Magazine "Forbes";

- Magazine "Liberali";

- Newspaper "Kronika+" ;

- Newspaper "Factmetri";

- $\quad$ Online portal www.new.vitube.ge;

- Online portal www.media.ge;

- $\quad$ NGO - Media Development Fund (MDF);

- Research organization "IPM" media monitoring service;

- $\quad$ TV 9 (in Poti);

- $\quad$ TV Company "L-TV"(in Lagodekhi);

- Newspaper "The Trialeti Express";

- $\quad$ Newspaper "The P.S. ( Imereti);

- TV Company "Borjomi";

- Newspaper "The Kakhetis Khma";

- Newspaper "Chemi Kharagauli";

- Regional TV Company "Metskhre Arkhi".

Demographic data of the employers $(n=25)$ : $64 \%$ from questioned respondents $(n=16)$ are female, $36 \%(n=9)$ male, $64 \%$ chose anonymity, thus they were given special codes (from the respondent 01 to 09). According to age, the highest percentage goes to the questioned respondents from 36 to $55(72 \% n=18)$, under $35-20 \%(n=5)$ and over $56-8 \%(n=2)$.

Educational background: All questioned respondents have higher education. Among them employers with a Master's degree dominate. This is $68 \%(n=17)$ of the questioned respondents and the rest $32 \%(n=8)$ can be divided equally between the respondents with $B A(n=4)$ and $\operatorname{PHD}(n=4)$ degrees.

\section{Main findings}

The research answered the three abovementioned questions as follows:

RQ1: According to what criteria are entry-level journalists employed in Georgia?

The research revealed that social and professional connections enhance employment possibilities. For the majority of the employers, professional and personal recommendations are important while choosing candidates for an internship. At the same point, employers admit that there is certain difference between internship and trial periods. Interns are paid in only $40 \%$ of questioned media organizations. From this point of view, improvement of internship practice is a challenge in Georgia.

Besides gaining professional experience and adjusting competences, an internship is an opportunity for broadening networks and connectivity for journalists, which will help them to find jobs in the future. For starting an internship practice, professional and/or personal recommendations are important for $89 \%$ of employers. As for employment, only $59 \%$ think that this factor matters.

\section{RQ2: What specific knowledge and skills are more attractive for employers?}

In Georgia, while employing journalists, writing and editing skills are the most important. Eighty-eight percent of participating employers think that these particular skills are important or very important, 76 percent considers that the ability to work on/meet deadlines is significant. The same percentage considers that tech-skills are important, $80 \%$ - the ability to select and process information. For $52 \%$ of employers give preference to having 'profound knowledge' in a particular sphere. 
For employers in Georgia, an employee's ability to work on tight deadlines is more important than a willingness to work under pressure; we can thus suppose that employers in Georgia do not perceive working on tight deadlines as a stressful situation. Whereas in other research (Venger, Owens, 2013) these two variables are mentioned on the same level. As a perspective of the study, we can research how students gain these skills at Universities.

For our employers, the following personal qualities of entry-level journalists are very important: team-work oriented, high sense of responsibility, communication skills, curiosity, tolerance, ability to manage (control) emotions and timemanagement.

\section{RQ3: Do employers take into consideration the University, qualifications and earned degrees?}

Unlike other research cases where the diploma from an elite university is an additional bonus for employment, Georgian research does not clearly name such Universities. However, for most (72\%) employers the status of the University is still important only for "general information and not for decision-making" as they say.

For $28 \%$ of employers, a degree in journalism has no importance at all. Exactly the same percentage says that a degree in journalism is a desirable attribute for hiring. Only $16 \%$ considers that a diploma is necessary and $16 \%$ claims that it is preferable to have additional educational experience in other spheres (e.g. Political science, economy, arts etc.). Other $24 \%$ considers that having previous work experience in media is a priority. From the employers point of view, graduates gain more theoretical knowledge and poor "skill-based" practical competences at universities in Georgia. While employing journalists, $84 \%$ of the questioned employers give priorities to competences gained in other spheres rather than journalism. The respondents mention that specific field competences are important while working on particular topics. The absolute majority of those questioned support the idea that gaining practical knowledge and skills is crucial.

It turned out, that $44 \%$ of the questioned respondents teach at higher-education institutes, and still, $60 \%$ have never discussed the competences (which are necessary for journalists) with academic staff, deans of media schools and/or administration. They suggest that improvement of networks, communications and exchanging ideas about curricula between employers and educators is crucial for development. In further research, interviewing people from the education sector will be a subject of our interest.

Employers list the number of issues, which are correlated, with the requirements of accreditation standards of high educational institutes (HEI) in Georgia. According to the regulations, accreditation standards are met if:

- $\quad$ the program objectives are clearly defined and achievable and take into consideration labor market demands;

- The mechanism of stakeholders' (employers, academic staff, students, graduates) participation in the establishment of program learning outcomes and program development, is established and implemented;

- The institution supports students' involvement in extra-curricular activities, and also offers them components for developing practical skills;

- The institution aims to internationalize its teaching and scientific work as well as the employability of its graduates;

- The infrastructure and technical equipment of the institution ensures the achievement of program learning outcomes;

- Program staff has necessary competences required for the achievement of intended learning outcomes of the component they teach etc. (see more on www.eqe.ge. last visit February 2018).

From this point of view, employers produced recommendations in the following directions:

Improvement of Competence based education via following descriptors: Knowledge and understanding, Applying knowledge, Making judgments, Communications skills, Learning skills, Values. In particular, employers wish to improve knowledge in media law and ethics, verbal and writing skills, knowledge and using new technologies, improving audiovisual art techniques, knowledge and usage of new and social media platforms, having necessary skills for managing a converged newsroom, development of beat journalism etc. According to employer opinion, the students at Universities gain more theoretical knowledge than practical. For the majority, practical knowledge is essential. They acknowledge that by supporting internship programs students gain practical skills, and in general they literary suggest "less theory and more practice". 
As to the educators: qualification is a matter of importance. From this point of view, employers pay attention to the attraction of those lecturers who "have considerable practice in journalism and know all the practical details which will be useful for students in the future."

Improvement of infrastructure and providing students with updated text books/manuals, development of the beatjournalism.

Internationalization: Employers pay attention, to increase the number of exchange programs (with European Universities); necessity of inviting foreign professors; intensive teaching of foreign languages; upgrading teaching methods.

\section{Recommendation}

The research revealed that the majority of surveyed employers (60\%) do not pay a salary to interns. From this point of view, it is desirable to encourage cooperation between higher-educational institutions and employers via paid internship. In particular, a component of double degree and qualification might be the optional model. In this model, students gain knowledge and skills directly from the employers, have sessions and practice on the employers, basis. However, at the same time students, attend additional theoretical courses at University. For the development of such kind of credit-related courses, a university pays money (part from the fees) to the employer, who in turn, pays part of this money to the intern.

The research revealed that there is no permanent effective practice of communication between employers and educators. It is desirable to create and develop such a platform of communication, to hold different events (forums, seminars, conferences) where interested groups will have a chance for dialogue. This will help to create programs focused on the labor market and programs based on competences, it will also help to sophisticate and develop the labor market. To strengthen formal and informal connections between University and the labor market, it is preferable to involve practitioners and potential employers in the educational process; this is an additional possibility for employing young journalists.

Research showed that for the majority of our employers, practical skills are important. Especially writing and editing skills. Practical teaching should be the exact subject of attention while modernizing programs.

Research revealed that in Georgia, the annual number of graduates who have qualifications in journalism, mass communication or major in journalism (ECTS: 120 credits) is unknown. Being a journalist does not require any regulations, which is why we often have cases of migration from one occupation to a media sector. It may be a good impulse for the development of the beat journalism, though only in those cases when a future journalist has appropriate competences for this profession. From this point of view, admitting the possibility of giving dual qualification/double major (on an undergraduate level) would be an attractive offer (e.g. from 240 ECTS a student can accumulate 120 in journalism studies and 120 in another specialty). In Georgia, by law, there is no possibility of providing a dual qualification. In spite of various changes over the last ten years referring to this law, on the BA level, qualification of two majors has not been recognized and admitted. Our recommendation is to discuss and advocate for this amendment.

\section{References}

[1] Andreas Veglis and Andreas Pomportsis, Journalists in the Age of ICTs: Work Demands and Educational Needs, Journalism \& Mass Communication Educator, 2014, Vol 69 (1) 61-75, jmce.sagepub.com, Downloaded from jmc.sagepub.com by guest on October 8, 2016.

[2] Lee B. Becker, Jeong Yeob Han, Donna Wilcox, and Tudor Vlad, The Effects of Preuniversity Study of Journalism on Entry to the Job Market, Journalism \& Mass Communication Quarterly, 2014, Vol. 91(2) 344356, 2014, jmcq. sagepub.com, Downloaded from jmq.sagepub.com at Tbilisi State University on October 9 , 2016

[3] Deb Wenger and Lynn C. Owens, An Examination of Job Skills Required by Top U.S. Broadcast News Companies and Potential Impact on Journalism Curricula, 2013, Electronic News, 7(1) 22-35; Downloaded from enx. sagepub.com at Tbilisi State University on October 9, 2016

[4] Gerbrand Tholen, Phillip Brown, Sally Power, Annabelle Allouch, The role of networks and connections in educational elites' labour market entrance Gerbrand Tholena, Research in Social Stratification and Mobility 34 (2013) 142-154. Published by Elsevier Ltd., Available online atwww.sciencedirect. com 
[5] Henrik Örnebring, Technology and journalism-as-labour: Historical perspectives, University of Oxford, UK, Journalism 11(1) 57-74, 2010, http://jou.sagepub.com, downloaded from jou.sagepub.com at Tbilisi State University on October 10, 2016, p. 57

[6] Huang, E. (2006) 'Facing the Challenges of Convergence: Media Professionals' Concerns of Working across Media Platforms', Convergence 12(1): 83-98

[7] Rivera, L. A. (2011). Ivies, extra curriculars, and exclusion: Elite employers' use of educational credentials. Research in Social Stratification and Mobility, 29 (1), 71-90.

[8] Singer, J. B. (2004) 'More than Ink-stained Wretches: The Resocialisation of Print Journalists in Converged Newsrooms', Journalism and Mass Communication Quarterly 81(4): 838-56. 